\title{
LAS PALABRAS, LOS GESTOS Y LO ABSOLUTO EN LA HORA DE LA ESTRELLA Y EN UN SOPLO DE VIDA DE CLARICE LISPECTOR.
}

\author{
Maria Laura Iglesias*
}

\section{Resumen:}

Estos libros presentan temas recurrentes en la obra de Clarice: la crisis del alma, la problemática relación entre autor y personajes, el pasaje sin quiebres de lo narrativo a una profunda y casi mística reflexión sobre el ser y la existencia, la presencia de la muerte. Clarice lucha en forma continua consigo misma, con sus personajes, que constituyen una prolongación de sí y lucha por concretarse, conscientemente, en el lenguaje.

Palabras claves: crisis, alma, ser, reflexión, muerte, lucha, lenguaje, autor y personajes

WORDS, GESTURES AND THE ABSOLUTE IN THE HOUR OF THE STAR

AND BREATH OF LIFE, BY CLARICE LISPECTOR

\begin{abstract}
:
These books introduce recurrent themes of Clarice's work: the crisis of the soul, the complicated relation between author and characters, the passage without interruption of narrative to a deep and almost mystical reflection of the being and the existence, the attendance of death. Clarice fights against herself through her characters. They are an extension of herself and she fights to materialize this struggle, consciously, in language.
\end{abstract}

Key-words: crisis, soul, been, reflection, death, fight, language, author and characters

\footnotetext{
* Licenciada en letras (Universidad de Palermo), maestranda de la Maestría de Literatura española y latinoamericana (Universidad de Buenos Aires), abogada (Universidad de Belgrano), Magíster en derecho y administración de justicia (Universidad Austral). Secretaria del Juzgado Civil y Comercial núm. 8, del departamento judicial de San Isidro, provincia de Buenos Aires. E-mail: mlig6411@yahoo.com.ar
} 
Toda narración es un misterio y su forma privilegiada es sin duda la novela. Pero ella más que espejo es espejismo. El narrador en la mayoría de las novelas es una ausencia, a lo sumo una voz. Pero en las obras que aquí nos proponemos analizar, La hora de la estrella y Un soplo de vida, esta ausencia, se vuelve una presencia, presencia particular y significativa, cuya clave intentaremos desentrañar.

En este análisis hemos querido destacar la idea de la novela como audición. Quien sabe escuchar (quien sabe leer) debe percibir la voz del autor, la del narrador, la de cada personaje. En nuestro análisis las voces de Clarice, su aparición o desaparición en las diferentes voces asumidas. La vista es la que establece el mundo, pero es el oído el que capta el sentido de sus voces. La voz humana no es sólo sentido, ni siquiera sentido personal: es palabra. En la obra de Clarice Lispector, asistimos a una constante reflexión sobre el lenguaje y sobre los límites de la palabra. Más allá de estos límites, está el gesto. Walter Benjamin ha definido el gesto a partir del análisis del teatro de Bertolt Brecht:

\begin{abstract}
Le théâtre épique est "gestuel". Dans quelle mesure il sera en même temps poétique au sens habituel du terme es une autre question. Le geste es son matériau et l'utilisation adécuate de ce matériau est sa mision. Vis à vis des declarations et affirmations foncièrment trompeuses des gens d'une part, vis à vis du caractère complexe et impenetrable de leurs actions d'autre part, le geste a deux aventages. D'abord, on ne peut le contrefaire que dans une certaine mesure, et cela d'autant moins qu'il 'est plus banal et plus habituel. Ensuite il a, au contraire des actions et enterprises des gens, un commencement définissable et une fin définisable. Cet aspect strictment, carrément délimité de chaque élément d'une attitude, qui apparaît cependant comme un tout dans un flot vivant, est meme un des phénomènes dialectiques fondamentaux du geste. Il en résulte une conséquence importante: nous retenons d'autant mieux les gestes que nous interrompons plus fréquemment celui que les fair. C'est pourqoui l'interruption de l'action a un rôle de premier plan dans le théâtre épique. 1
\end{abstract}

Clarice expresó claramente, también, el límite de la palabra y lo que está detrás de él ciñendo un lenguaje que es "[...] escuálido y estructural como resultado de escuadras, compases y agudos ángulos de estrecho enigmático triángulo."2

Detrás del lenguaje está el gesto, que en la obra de Clarice se traduce en una escritura fragmentaria, donde las palabras, vaciadas de todo sentido anterior, alcanzan su máxima consagración.

\footnotetext{
${ }^{1}$ BENJAMIN, 1969, p. 9 y ss.

${ }^{2}$ LISPECTOR, 1999, p. 8.
} 
También señalará "tengo miedo de escribir, es tan peligroso. Quien lo ha intentado, lo sabe. Peligro de revolver en lo oculto - y el mundo no va a la deriva, está oculto en sus raíces sumergidas en las profundidades del mar. Para escribir tengo que colocarme en el vacío". 3 Su obra es una constante lucha entre la expresión y el silencio. La escritura debe captar el instante, la iluminación; por eso su obra es fragmentaria. Por otra parte, postula un trabajo constante con las palabras, pero en sus últimas obras $-L a$ hora de la estrella y un Soplo de vida, ambas de 1977 - aparece cierta desazón sobre la utilidad del lenguaje.

"Yo quisiera escribir un libro ¿Pero dónde están las palabras? Se han agotado los significados. Como sordos y mudos nos comunicamos con las manos."4

"Estoy absolutamente cansado de la literatura; sólo la mudez me hace compañía. Si todavía escribo, es porque no tengo nada más que hacer en el mundo mientras espero la muerte. La búsqueda de la palabra en la oscuridad."5

La novela es un complejo y sutil juego de voces. Se presenta como un registro. $\mathrm{Su}$ riqueza se funda en una polifonía, que recoge su profundidad. Decir entre autor, narrador y personaje implica, fundamentalmente, distinguir entre los dos primeros. El narrador no es siempre el autor: su misión es contar. Por otra parte, el autor, no es simplemente el hombre escribiente. El autor es la categoría de escritor que pone su oficio, todo su pasado de información literaria y artística, su caudal de conocimientos e ideas al servicio del sentido unitario de la obra que elabora. Esta entidad que llamamos autor asoma muchas veces en el libro, detrás del narrador, no confiando plenamente en él, arreglando, componiendo, aclarando. Esta imagen de autor no es una para todos los libros del mismo escritor, sino diferente para cada uno de ellos. En nuestro tiempo, la revolución se produce en el arte y en la crítica de la novela cuando el lector pregunta ¿quién habla?

Michel Foucault en su conferencia “¿Qué es un autor?” postula la indiferencia con respecto al autor, como lema o principio fundamental de la ética contemporánea. Manifiesta que "[...] la marca del escritor ya no es sino la singularidad de su ausencia, le es preciso ocupar el papel de muerto en el juego de la escritura [...]."6

\footnotetext{
${ }^{3}$ Ibid., p. 47.

${ }^{4}$ Ibid., p. 47.

${ }^{5}$ LISPECTOR, 2006, p. 66.

${ }^{6}$ FOUCAULT, 1999, p. 329 y ss.
} 
Sin embargo Giorgio Agamben, partiendo del análisis de esta conferencia de Foucault y retomando la idea de gesto Brechtiano, sostiene que "El mismo gesto, que niega toda relevancia a la identidad del autor, afirma sin embargo su irreductible necesidad..." Asimismo, postula que "si llamamos gesto a aquello que permanece inexpresado en todo acto de expresión, podremos decir, entonces [...] que el autor está presente en el texto solamente en un gesto, que hace posible la expresión en la medida misma en que instaura en ella un vacío central [...].",7

En la novela el autor da la palabra a un narrador y éste eventualmente a sus personajes. En La hora de la estrella y en Un soplo de vida, aparece el gesto de Clarice que le da la palabra, en la primera a Rodrigo S.M., personaje-autor y en la segunda, al personaje-autor. En estas novelas el dialogo está siempre más o menos teñido, es decir, la voz del narrador permanecerá siempre en el primer plano de la audición. La novela es una realidad secundaria: en ellas el diálogo entraña ese complicado juego de espejos que es su propia naturaleza.

La extraña complejidad de estas novelas proviene de la voz del narrador, o mejor dicho, de las diferentes voces que el narrador modula a través de la suya, como un juego sutil de espejos. El narrador no es el autor, es el personaje autor (Rodrigo S.M. y simplemente “autor"). Detrás de ellos está la novela. Es preciso aceptar la paradoja: el autor - Clarice Lipector-crea el mundo de sus novelas; pero también este mundo se crea a sí mismo a través de ella, la transforma y la obliga a entrar en el juego de las transformaciones para manifestarse a través de él. Las interrupciones de la palabra muestra sus límites y es precisamente allí donde aparece el gesto de autor de Clarice Lispector, gesto que muestra el juego entre las palabras del narrador y al mismo tiempo donde aparece la pregunta: “¿qué importa quien habla ha dicho alguien que importa quien habla?", frase de Beckett, citada por Agamben en "El autor como gesto", donde sostiene que "el problema de la escritura no es tanto la expresión de un sujeto, como la apertura de un espacio en el cual el sujeto que escribe no termina de desaparecer: 'la marca del autor está sólo en la singularidad de su ausencia." "8

Se presenta una tensión difícil de resolver entre autor y narrador. El primero está siempre presente y resulta difícil mantenerlo callado. Si la voz del narrador se presenta como legítima, la del autor aparece como intrusa. Y si el narrador siempre

\footnotetext{
${ }^{7}$ AGAMBEN, 2009, p. 81 y ss.

${ }^{8}$ AGAMBEN, 2009, p. 81 y ss.
} 
acierta cuando habla y cuando calle, el autor sólo acierta cuando calla. Pero, en La hora de la estrella, Clarice no busca involucrarse en la historia de Macabea, por eso le da la palabra a Rodrigo S.M., es el gesto de la autora. En Un soplo de vida, el personaje autor crea su propio personaje y se establece un diálogo entre ellos:

\begin{abstract}
El resultado de todo eso es que tendré que crear un personaje, más o menos como lo hacen los novelistas, para conocer a través de su creación. Porque solo no lo consigo: la soledad, la misma que existe en cada uno me hace inventar...Escribo para aprender. Me he elegido a mí y a mi personaje, Ángela Pralini, para que yo pueda entender tal vez, a través de nosotros, esa falta de definición de la vida.9
\end{abstract}

En ambas novelas la tensión entre autor y narrador hace que nos demos cuenta de ella, de sus polos. El autor habla a través del narrador, el narrador "disimula" juicios y opiniones del autor. Pero basta que el narrador ceda un poco para que se distienda y aparezca la voz del autor. En ambas novelas el narrador habla hipostasiándose al personaje-autor y su visión no es monoscópica ni parcial. La voz del narrador constituye la única realidad del relato. Es el eje de las novelas. Puede que no oigamos en absoluto la voz del autor ni la de los personajes. Pero sin el narrador no hay novela. El narrador tiene una misión, la de contar. Se sitúa no en el plano del enunciado, sino en el de la enunciación.

Cuando el narrador es un personaje de la historia, como ocurre en La hora de la estrella y en Un soplo de vida, la novela se presentan como una unidad cerrada, un conjunto en sí mismo. La atención del lector no se reparte constantemente entre un narrador externo a la historia y la gente que está dentro de ella. Al ser el narrador un personaje y, en nuestro caso, el personaje-autor, se produce cierta unidad de carácter en las obras; más aún cuando es una personalidad concreta, la del autor - Clarice Lispector - y no algún relator anónimo o nebuloso, se agrega un elemento dramático al dramatizar al narrador. La primera persona cambia automáticamente las palabras del autor en palabras del personaje. La progresión de autor a personaje está completa.

¿Hasta dónde soy yo y en dónde comienzo a ser Ángela? ¿Somos frutos del mismo árbol? No: Ángela es todo lo que yo querría ser y no he sido. ¿Qué es ella? Ella es las olas del mar. Mientras yo soy un bosque espeso y sombrío. Yo soy en el fondo. Ángela se esparce en esquirlas brillantes. Ángela es mi vértigo. Ángela es mi reverberación y, siendo emanación mía, ella es yo.

\footnotetext{
${ }^{9}$ LISPECTOR, 1999, p. 19.
} 
Ángela parece algo íntimo que se ha exteriorizado. Ángela no es un “personaje".Es la evolución de un sentimiento. Una idea encarnada en el ser. 10

“¿Habré creado a Ángela para tener un diálogo conmigo mismo? Inventé a Ángela porque necesito inventarme. Ángela la asombradiza". ${ }^{11}$

Raúl Antelo afirma que Clarice Lispector

\begin{abstract}
arma una escritura que constantemente circunda la cuestión de la ética de lo neutro, desde la convicción de que la fuerza de su lenguaje no reside en consolidar una hermenéutica vanguardista, en busca de una pretendida identidad nacional, sino en diseñar la inconclusiva consistencia estriada de un sujeto múltiple. En ese sentido, la suya es una escritura pautada por un constante diferimiento de la intencionalidad, como si esa fuera la mejor estrategia tendiente a la aparición de la apertura y al evento de la ausencia, de tal modo que Clarice se sitúa en un lugar ambiguo, a mitad de camino entre la memoria identitaria, que debe ser abandonada o vaciada, y la voz de lo que aún no somos pero, pese a todo nos constituye. 12
\end{abstract}

En Clarice se percibe la fuerza del lenguaje y sobre todo los límites de las palabras. En ella es el lenguaje el que habla, y se configura aquello que señalaba Barthes "escribir consiste en alcanzar, a través de una previa impersonalidad-que no se debería confundir en ningún momento con la objetividad castradora del novelista realista-ese punto en el cual sólo el lenguaje actúa, "performa”, y no "уо". 13

Hay en Clarice un gesto, que se limita a mezclar su escritura y a otorgar la palabra a sus personajes (Rodrigo S.M. y al autor-personaje), quienes relatan la historias y se relacionan con los restantes personajes. Así, percibimos en las obras analizadas una lucha por lograr un equilibrio entre la palabra escrita y los silencios significativos, a veces, más elocuentes, en ciertas ocasiones, que las propias palabras. Dirá el autorpersonaje de Un soplo de vida "escribiendo me libro de mí y puedo entonces descansar". ${ }^{14}$

\title{
Texto y metatexto en la estructura de las novelas.
}

\footnotetext{
${ }^{10}$ LISPECTOR, 1999, p. 28.

${ }^{11}$ Ibid., p. 29.

${ }^{12}$ ANTELO, Qué significa Clarice Lispector para la historia brasileña? [apunte de cátedra. Sin año de edición ni página].

${ }^{13}$ BARTHES, 1987, p. 3 y ss.

${ }^{14}$ LISPECTOR, 1999, p. 21.
} 
La hora de la estrella es una de las últimas novelas de Clarice Lispector y en ella se narra la historia de una pobre muchacha, llamada Macabea, que vive en el nordeste de Brasil. En Un soplo de vida, hay un gesto de Clarice que da la palabra al autor-personaje, éste a su vez tiene la necesidad de crear su propio personaje, para poder expresarse. Así nacerá Angela Pralini. A través de ella quiere "iniciar una experiencia y no sólo ser víctima de una experiencia que sucede sin que yo la autorice. De ahí mi invención de un personaje. También quiero despejar, además del enigma del personaje, el enigma de las cosas". ${ }^{15}$

En estos libros se presentan los temas recurrentes que aparecen a lo largo de toda la obra de Lispector: las crisis de alma que presupone toda creación, la lucha entre pensamiento, vivencia y escritura, la problemática relación entre autor y personaje, el pasaje de lo narrativo a la reflexión sobre el ser y la existencia y la presencia de la muerte.

Se advierte una lucha continua en la autora. Lucha consigo misma, lucha por la prolongación de sí, representada en sus personajes y el ansia por concretarse en el lenguaje.

\section{La hora de la estrella}

La novela se abre con una dedicatoria de autor, en realidad Clarice Lispector, de cuyo texto inferimos que Clarice se plasmará en una figura tan real como la del personaje narrador, Rodrigo S.M., máscara masculina de Clarice, quien declara:

\footnotetext{
Me propongo escribir algo que no sea complejo, aunque esté obligado a usar palabras que ustedes rechazan. El relato decido - con falso arbitrio- va a tener siete personajes y yo soy uno de los más importantes, está claro. Yo, Rodrigo S.M.16
}

La historia es, en sí misma, simple y lineal. Se presenta, por una parte, la narración - el texto y su palabra explícita- y por otra, el metatexto, con sus continuas reflexiones.

En relación con el texto, la historia narrada es clara y puede ser resumida brevemente. Macabea es una pobre muchacha nordestina, a quien le cuesta expresarse

\footnotetext{
${ }^{15}$ Ibid., p. 19.

${ }^{16}$ LISPECTOR, 2006, p. 14.
} 
en palabras. Pero, paradójicamente, se desempeña como dactilógrafa. Macabea es tan tonta que a veces "sonríe a los otros en la calle. Nadie le responde la sonrisa porque ni siquiera la miran". ${ }^{17}$ Nadie repara en ella, tampoco su novio Olimpico de Jesús, ignorante y soberbio, quien no la descubre en su simplicidad y la abandona para unirse a Gloria, la mejor amiga de Macabea.

Tampoco logra apreciar su simplicidad madame Carlota, la vidente a la que recurre Macabea para vislumbrar su futuro. Esta nigromante la engaña e ilusiona con un futuro promisorio, conocerá a un extranjero rubio y rico llamado Hans, que se casará con ella y la tratará como una reina. Al final, cuando Macabea alienta ciertas esperanzas, instigada por las mentiras de madame Carlota, muere atropellada por un automóvil, un Mercedes Benz, que la arrolla cuando intenta cruzar la calle. El auto no se detiene y Macabea muere después de pronunciar su última frase que nadie comprende: "En cuanto al futuro". ${ }^{18}$

Este libro podría presentarse como una historia sencilla y simple, donde aparece la injusticia de la vida. Sin embargo, Lispector, se propone analizar temas recurrentes en su obra, en este caso, el absurdo existencial, que sólo es superado, en determinados momentos, por los placeres que, en forma limitada, nos podemos proporcionar, al igual que Macabea.

Recurrentemente, planteará el narrador la insignificancia de Macabea, su invisibilidad, “[...] Nadie la miraba en la calle, ella era café frío [...]”. ${ }^{19}$ Sin embargo, Rodrigo S.M. ama a Macabea, así dirá:

Sí, estoy enamorado de Macabea, mi querida Maca, enamorado de su fealdad y de su anonimato total, pues ella no existe para nadie...Yo quisiera que ella abriese la boca para decir: -Estoy sola en el mundo y no creo en nadie, todos mienten, a veces hasta en la hora del amor, yo no veo que una persona hable con otra, la verdad sólo me llega cuando estoy sola. 20

\section{La función del narrador}

\footnotetext{
${ }^{17}$ Ibid., p. 12.

${ }^{18}$ Ibid., p. 79.

${ }^{19}$ LISPECTOR, 2006, p. 27.

${ }^{20}$ Ibid., p. 42.
} 
En esta novela la función del narrador es muy importante. Hay un gesto de Clarice que le otorga la palabra a Rodrigo S.M., personaje autor, para no involucrarse en la historia de Macabea. Reflexiona constantemente sobre el hecho de la escritura, que en el caso de Clarice Lispector, implican una meditación sobre los interrogantes del vivir. Introduce numerosos comentarios, que son ajenos a la acción y que siguen el hilo de la asociación libre.

La historia se presenta como un juego de máscaras entre Clarice, Macabea y Rodrigo S.M.

También se advierte una cuestión de género, pues Clarice le da la palabra a Rodrigo S.M, que es un hombre. Por su parte, éste relata la muerte de Macabea que es mujer.

El mismo narrador advierte que la palabra está amenazada, así expresa "medito sin palabras y sobre la nada. Lo que me confunde la vida es escribir [...]". ${ }^{21}$

También dirá: "No es fácil escribir. Es duro como parir rocas. Pero saltan chispas y astillas como aceros pulidos". ${ }^{22}$ Las palabras en Clarice son como astillas de acero pulido. La palabra es rigurosa, porque el adorno la destruiría: "escribo muy simple y muy desnudo. Por eso hiere". ${ }^{23}$

En la historia, el narrador interviene constantemente y explica sus estados de ánimo al escribir el texto. De esta forma, pone de manifiesto la condición reflexiva de la escritura y su precariedad. Esta condición reflexiva se presenta como una escena teatral, como un dialogo entre el narrador y el personaje, entre creador y criatura: "No soy un intelectual, escribo con el cuerpo. Y lo que escribo es una niebla húmeda. Las palabras son sonidos traspasados de sombras que se entrecruzan desiguales, estalactitas, encaje, música de órgano transfigurada". ${ }^{24}$

Estos conceptos acerca del lenguaje se suceden a lo largo de la historia. Así, al hablar de Macabea, el narrador expresa su propio anhelo: "Quisiera que ella abriese la boca para decir: -Estoy sola en el mundo y no creo en nadie, todos mienten, a veces hasta en la hora del amor, yo no veo que una persona hable con la otra, la verdad sólo me llega cuando estoy sola". ${ }^{25}$

\footnotetext{
${ }^{21}$ Ibid., p. 9.

${ }^{22}$ Ibid., p. 45.

${ }^{23}$ Ibid., p. 46.

${ }^{24}$ LISPECTOR, 2006, p. 18.

${ }^{25}$ Ibid., p. 65.
} 
Aparece, también, al final de la novela otra reflexión sobre el valor cuestionado de la palabra, cuando Macabea habla con madame Carlota: “¿Vos sabés qué quiere decir alcahueta? Yo uso esa palabra porque nunca he tenido miedo de las palabras. Hay gente que se asusta del nombre de las cosas. ¿Tú tienes miedo a las palabras, cielo? - Lo tengo, sí, señora". ${ }^{26}$

El narrador busca su propia identidad a través del hallazgo de verdad conceptual de un verbo. Así en una primera aproximación, admitiendo su condición de escritor, dice: "Por fortuna lo que voy a escribir ya debe estar, por cierto, sin duda y de algún modo escrito en mi.",27

Pero, luego intenta otra respuesta: "Sigo una oculta línea fatal. Estoy obligado a buscar una verdad que me supera. ¿Por qué escribo sobre una joven que ni aún tiene una pobreza con adornos?" 28

Finalmente afirma:

Escribo porque no tengo nada que hacer en el mundo: estoy de sobra y no hay lugar para mí en la tierra de los hombres. Escribo por mi desesperación y mi cansancio, ya no soporto más la rutina de ser yo y si no existiese la novedad continua que es escribir, me moriría simbólicamente todos los días. 29

Estas reflexiones no se limitan a sólo a esta novela. En toda la obra de Clarice Lispector hay una continuidad y una unidad, por lo cual éstos interrogantes pueden hallarse en sus otras novelas.

La historia narrada no es lineal en su escritura, sino que se cruza con el metatexto, donde el tiempo no transcurre y donde el mismo acto de escribir aparece cuestionado al no captar en plenitud el absoluto presentido y percibido.

\section{Un soplo de vida (Pulsaciones)}

Este libro, como señala Olga Borelli, fue escrito por Clarice Lispector, entre 1974 y 1977 , en vísperas de su muerte. ${ }^{30}$

\footnotetext{
${ }^{26}$ Ibid., p. 71.

${ }^{27}$ Ibid., p. 21.

${ }^{28}$ Ibid., p. 22.

${ }^{29}$ Ibid., p. 22.

${ }^{30}$ LISPECTOR, 1999, p. 9.
} 
En esta novela también aparece un gesto de Clarice que le da la palabra al narrador, quien se convertirá en el personaje-autor, que a su vez, creará a su propio personaje: Angela Pralini.

Pero, también, podemos advertir un juego de espejos entre el autor-personaje y Angela Pralini. Ella se presentará como un doble de Clarice. Así Ángela dirá: “En mi libro La ciudad sitiada hablo indirectamente del misterio de la cosa. La cosa es un animal especializado e inmovilizado. Hace años también describí un armario. Después fue la descripción de un reloj inmemorable llamado Sveglia $[\ldots]^{31}$ y "En El huevo y la gallina hablo de la grúa. Es una tímida aproximación mía a la subversión del mundo vivo y del mundo muerte amenazador", 32

En este libro no aparece una historia sencilla como ocurre en La hora de la estrella, sino que el autor-personaje explica a Ángela, describe sus pasiones, sus sentimientos, su actividad como escritora. Presentará, como señala el narrador, rápidos vislumbres de él y de su personaje. Ángela representa a Clarice. A lo largo del libro aparece una constante reflexión sobre la escritura y sobre los temas recurrentes en la obra de Clarice, la crisis del alma que supone toda creación, la lucha entre pensamiento, vivencia y escritura, la problemática relación entre autor y personaje, el paso de tiempo y la presencia de la muerte: "En cada palabra late un corazón. Escribir es esa búsqueda de la veracidad íntima de la vida". ${ }^{33}$

\footnotetext{
Escribo para aprender. Me he elegido a mí y a mi personaje, Ángela Pralini, para qué yo pueda entender tal vez, a través de nosotros, esa falta de definición de la vida. La vida no se adjetiva. Es una mezcla en un crisol extraño pero que me hace, en última instancia, respirar. $\mathrm{Y}$ a veces jadear. $\mathrm{Y}$ a veces apenas respirar. Pero a veces también está el sorbo profundo de aire que alcanza hasta el fino frío del espíritu, sujeto al cuerpo por ahora.34
}

"Si este libro saliese a la luz alguna vez, que de él se aparten los profanos. Pues escribir es recinto sagrado en el que no tienen entrada los infieles [...] La inspiración es como un misterioso aroma de ámbar. Llevo un trozo de ámbar conmigo [...]". ${ }^{35}$

Señalamos, al comienzo, que toda narración es un misterio y que su forma privilegiada es la novela y que ésta más un juego de espejos es espejismos. Esta

\footnotetext{
${ }^{31}$ Ibid., p. 9.

${ }^{32}$ Ibid., p. 100.

${ }^{33}$ Ibid., p. 17.

${ }^{34}$ LISPECTOR, 1999, p. 19.

${ }^{35}$ Ibid., p. 21.
} 
descripción es analizada por el autor-personaje al comienzo de su relato, "Tuve un sueño nítido inexplicable: soñé que jugaba con mi reflejo. Pero mi reflejo no estaba en un espejo, sino que reflejaba a otra persona que no era yo". 36

“¿Inventé por causa de ese sueño a Ángela como mi reflejo? Todo es real, pero se mueve des-pa-cio-sa-mente en cámara lenta". ${ }^{37}$

Para crearla tengo que arar la tierra. ¿Hay alguna avería en el funcionamiento del sistema de ordenadores de mi nave mientras surca los espacios en busca de una mujer? Ordenador con cristales de sílex puro, con el equivalente a millares de transistores microscópicos grabados en la superficie pulida y reluciente con el sol a plomo en su espejo, Ángela espejo.38

La propia Ángela dirá "El cuerpo tiene pena del cuerpo. Soy un espejismo: de tanto querer verme me veo". 39

El personaje-autor crea a Ángela, le da un soplo de su propia vida y la contrapone a él. Aparece, nuevamente, como en La hora de la estrella, la cuestión del género, pues el personaje-autor es un hombre y crea a Ángela, que es una mujer. Antes había creado a Macabea.

Ángela Pralini es fiesta de nacimiento. No sé qué esperar de ella: ¿tendré solamente que transcribirla? Debo tener paciencia para no perderme dentro de mí: vivo perdiéndome de vista. Me hace falta paciencia porque soy varios caminos, aún el fatal callejón sin salida. Soy un hombre que eligió el gran silencio. Crear a un ser que se contraponga a mí es posible dentro del silencio. 40

Una vez que recibí el soplo de vida que hizo de mí un hombre, soplo en ti que te vuelvas un alma. Te presento a mí, haciéndote visible en instantáneas que se suceden ya en medio de tu inauguración: tú no comienzas por el principio, comienzas por el medio, comienzas en el instante de hoy.41

“Ángela no sabe que es un personaje y, quién sabe, tal vez yo sea también un personaje de mí mismo". ${ }^{42}$

Hay un juego de máscaras narrativas. Un autor habla de un autor-personaje, quien crea a su vez, otro personaje que es Ángela, más importante que el propio autor.

\footnotetext{
${ }^{36}$ Ibid., p. 25

${ }^{37}$ Ibid., p. 25.

${ }^{38}$ Ibid., p. 26.

${ }^{39}$ Ibid., p. 106.

${ }^{40}$ Ibid., p. 27.

${ }^{41}$ LISPECTOR, 1999, p. 27.

${ }^{42}$ Ibid., p. 27.
} 
“Ángela no es un "personaje”. Es la evolución de un sentimiento. Una idea encarnada en el ser". ${ }^{43}$

En ambas novelas analizadas, hay un tratamiento particular de las palabras. Aparece una búsqueda constante de significados. En ambas el narrador es escritor pero no así los personajes creados. Macabea es mecanógrafa y Ángela, en cambio, es escritora. "Las palabras de Ángela son antipalabras: vienen de un abstracto lugar en ella donde no se piensa, ese lugar oscuro, amorfo y goteante como una caverna primitiva". ${ }^{4}$

También el narrador dirá:

\begin{abstract}
Soy el autor de una mujer que he inventado y a quien he dado el nombre de Ángela Pralini. Vivía bien con ella. Pero comenzó a perturbarme y me di cuenta que tenía que asumir de nuevo el papel de escritor para poner a Ángela en palabras, porque sólo entonces puedo comunicarme con ella. Escribo un libro y Ángela escribe otro: he quitado de ambos lo superfluo. Escribo a medianoche porque soy oscuro. Ángela escribe de día porque es casi siempre alegre luz. 45
\end{abstract}

Aparece, como señalamos, una búsqueda constante de significados. Pero Ángela se presenta como un significado.

El narrador (autor-personaje) señalará: "Y eso que intento escribir lo que ocurre con Ángela. No sirve de nada: Ángela es sólo un significado. ¿Significado suelto? Ella es la palabra que he olvidado". ${ }^{46}$

Ángela escribirá sobre objetos, analizará su aura, temas recurrentes en la obra de Clarice Lispector.

Así señalará Ángela: "Mañana comenzaré mi novela de las cosas". 47

"Escribir: yo me arranco las cosas a pedazos, así como el arpón entra en la ballena y le desgarra la carne [...]". 48

Ángela escribirá sobre las cosas - reloj, gramófono, el coche, el violín, el cubo de basura, un pendiente de oro, una bola redonda, el ascensor, ella se enamoró de la visión de las cosas, las resignifica.

"La cosa es lisa y llanamente la cosa. La cosa no es triste ni alegra: es cosa. La cosa tiene en sí un proyecto. La cosa es exacta". ${ }^{49}$

\footnotetext{
${ }^{43}$ Ibid., p. 28.

${ }^{44}$ Ibid., p. 35 ,

${ }^{45}$ Ibid., p. 33.

${ }^{46}$ Ibid., p. 56.

${ }^{47}$ LISPECTOR, 1999, p. 97.

${ }^{48}$ LISPECTOR, 1999, p. 97.
} 
En esta novela no aparece la narración de una historia simple y sencilla. La autora crea su novela a través de su personaje-narrador, pero este mundo también se crea a sí mismo a través de él y a través de su propio personaje - Ángela, que obliga a la autora a entrar en el juego de las transformaciones. Hay una materia que quiere decirse y es Ángela quien le dará forma y contenido. El narrador-personaje aparecerá como una imagen fugitiva, a veces, que irá de la autora de carne y hueso a su propio personaje imagen y semejanza de Clarice.

${ }^{49}$ LISPECTOR, 1999, p. 101. 


\section{REFERÊNCIAS}

AGAMBEN, Giorgio. El autor como gesto. In: . Profanaciones. 2. reimp. Buenos Aires: Adriana Hidalgo, 2009.

ANTELO, Raúl. ¿Que significa Clarice Lispector para la historia brasileña? [apunte de cátedra sin año de edición ni página]

BARTHES, Roland. La muerte del autor. In: EI susurro del lenguaje. Barcelona: Paidós, 1987.

BENJAMIN, Walter. ¿Qu ést que le théâtre épique. In: . Essais sur Bertolt Brecht. Paris: Fracois Maspero, 1969.

FOUCAULT, Michel. ¿Qué es un autor? In: Entre Filosofía y literatura. Buenos Aires: Paidós, 1999.

LISPECTOR, Clarice. Un soplo de vida. Madrid: Siruela, 1999. La hora de la estrella. Madrid: Siruela, 2006. 